\title{
Primary Hyperparathyroidism Associatiated with Aldosterone-Producing Adrenocortical Adenoma and Breast Cancer: Relation to MEN1 Gene
}

\author{
Munehiro Honda, Toshihiko TsUKADA*, Toshimitsu HorIUCHI, Reiko TANAKA**, \\ Ken YAmaguchi*, Takao OBARA**, Hiroshi MiYAKAWA, Tohru YAMAJI*** and Miyuki ISHIBASHI
}

\begin{abstract}
A rare case of primary hyperparathyroidism associated with primary aldosteronism and breast cancer is reported. A 44-year-old woman was admitted to our hospital to undergo surgical removal of breast cancer. She had hypertension with low serum potassium, and slightly but significantly elevated serum calcium levels. Further studies demonstrated an enlarged left superior parathyroid gland and a left aldosterone-producing adrenocortical adenoma. Blood pressure was controlled with spironolactone and nifedipine, and left mastectomy was done for breast cancer. The pathological diagnosis was scirrhous breast carcinoma. Although the postoperative course was uneventful, her serum calcium gradually and progressively rose to higher levels. Left superior parathyroidectomy and left adrenalectomy were then performed simultaneously. The pathological diagnoses of the resected parathyroid gland and adrenal gland were parathyroid chief cell adenoma and adrenocortical adenoma with hyperplasia of zona glomerulosa, respectively. To clarify if the occurence of these tumors may be related to MEN1 gene mutations, we analyzed MEN1 gene in this patient, and found a loss of heterozygosity of the MEN1 locus in the parathyroid adenoma and breast cancer. Thus, we conclude that an alteration of the MEN1 gene and/or another tumor suppressor gene located at the MEN1 locus on chromosome 11q13 may be responsible for the development of parathyroid adenoma and breast cancer in our patient suggesting that the clinical spectrum of MEN1 might include breast cancer. In addition, serum calcium should be interpreted with caution in primary aldosteronism, because hypercalcemia may be masked in the presence of aldosterone excess.
\end{abstract}

(Internal Medicine 43: 310-314, 2004)

Key words: multiple endocrine neoplasia type 1 (MEN1), MEN1 gene, loss of heterozygosity, breast cancer, primary hyperparathyroidism, primary aldosteronism

\section{Introduction}

Multiple endocrine neoplasia type 1 (MEN1) is an autosomal dominant inherited disorder characterized by the presence of hyperplasia or adenoma of the parathyroid gland, and tumors of the endocrine pancreas, and anterior pituitary (1). The responsible gene, MEN1, was mapped to chromosome 11q13 (2), and recently identified (3, 4). Since loss of heterozygosity ( $\mathrm{LOH})$ of the MENI locus is frequently observed in MEN1-related tumors, the MEN1 gene has been considered to be a tumor suppressor gene $(2,5-7)$. Allelic losses of DNA markers on chromosome 11q13, centered on the MENI critical region, in a substantial number of sporadically occuring parathyroid adenomas $(6,7)$, may further support the notion that the MEN1 tumor suppressor gene may also be the target of somatic inactivating lesions in sporadic endocrine tumors.

Although the parathyroid, pancreas and pituitary are most frequently affected in MEN1, it is well known that tumors may arise in a variety of organs apparently unrelated to MEN in this pathologic state. One of the rare associations with MEN1 is primary aldosteronism. Here, we report a patient with an unusual combination of primary hyperparathyroidism, primary aldosteronism and breast cancer. To determine whether the development of these tumors may be

\footnotetext{
From the Fourth Department of Medicine, Teikyo University School of Medicine, Kawasaki, *Growth Factor Division, National Cancer Research Institute, Tokyo and **Department of Surgery, Institute of Clinical Endocrinology, Tokyo Women's Medical College, Tokyo Received for publication July 8, 2003; Accepted for publication November 1, 2003

Reprint requests should be addressed to Dr. Miyuki Ishibashi, the Fourth Department of Medicine, Teikyo University School of Medicine, 3-8-3 Mizonokuchi, Takatsu-ku, Kawasaki, Kanagawa 213-8507
} 
Loss of Heterozygosity of the MEN1 Gene in Breast Cancer

related to MENI gene mutations, we analyzed the MENI gene in this patient. A possible alteration of calcium metabolism associated with primary aldosteronism was also examined in this study.

\section{Case Report}

A 44-year-old Japanese woman was admitted to our hospital on May 9, 1995, to undergo an operation for left breast cancer. She had no serious illness before, but complained of occasional left flank pain for the past three months. There was no known family history of MEN1. On admission, her blood pressure was 192/118 $\mathrm{mmHg}$ with a pulse rate of 86 beats/min. Palpation of the left breast revealed a firm nodule of the size of $1.5-\mathrm{cm}$ in diameter. The remainder of physical examination was not remarkable.

Laboratory examinations showed normal hemogram and normal liver function. Urine evaluation did not show any abnormalities. Serum albumin was $3.7 \mathrm{~g} / \mathrm{dl}$, blood urea nitrogen was $8.5 \mathrm{mg} / \mathrm{dl}$, and creatinine was $0.7 \mathrm{mg} / \mathrm{dl}$. A 24-hour creatinine clearance was estimated to be $77.4 \mathrm{ml} / \mathrm{min}$. Serum electrolyte values were as follows: sodium, $146 \mathrm{mEq} / l$; potassium, $3.1 \mathrm{mEq} / l$; and chloride, $108 \mathrm{mEq} / \mathrm{l}$. Serum calcium ranged from 10.2 to $10.4 \mathrm{mg} / \mathrm{dl}$, while phosphate from 2.1 to $2.4 \mathrm{mg} / \mathrm{dl}$. Urinary calcium excretion ranged from 138 to 203 $\mathrm{mg} /$ day. Serum alkaline phospatase was not elevated. No abnormal findings were observed in chest and abdominal X-ray films. An electrocardiogram revealed the presence of prominent $\mathrm{U}$ waves.

The patient had a definitely elevated plasma aldosterone concentration (29 ng/dl, normal range: 3-16 ng/dl). Plasma renin activity, on the other hand, was very low, and showed a limited increase (from less than 0.1 to $0.2 \mathrm{ng} / \mathrm{ml} / \mathrm{h}$ ) after stimulation with an intravenous injection of $20 \mathrm{mg}$ furosemide followed by standing for 2 hours. In addition, her plasma intact PTH level was $93 \mathrm{pg} / \mathrm{ml}$, which clearly exceeded the normal range (14-66 pg/ml). Basal plasma levels of other hormones including growth hormone, thyroid stimulating hormone, prolactin, ACTH, thyroxine, cortisol, gastrin, glucagon, and insulin were all within normal limits. She had normal fasting blood glucose.

Ultrasonography of the neck revealed enlargement of the left superior parathyroid gland, which was confirmed by a CT scan. ${ }^{131}$ I-adosterol scintigraphy during dexamethasone suppression showed an asymmetric uptake in the left adrenal region. A CT scan of the abdomen demonstrated a left adrenocortical tumor of $2 \times 3 \mathrm{~cm}$ in size. Based on these findings, a diagnosis of primary hyperparathyroidism associated with an aldosterone-producing adrenocortical adenoma was made.

Blood pressure was controlled with spironolactone and nifedipine, and left mastectomy was successfully done for breast cancer on June 8, 1995. The pathological diagnosis was scirrhous breast carcinoma (Fig. 1A). After the initiation of spironolactone therapy, her serum calcium gradually and progressively rose to higher levels $(10.4 \mathrm{mg} / \mathrm{dl}$ before spironolactone and $11.6 \mathrm{mg} / \mathrm{dl}$ after 8 weeks of spironolactone therapy), while plasma intact PTH levels were not significantly changed $(93 \mathrm{pg} / \mathrm{ml}$ before spironolactone and $86 \mathrm{pg} / \mathrm{ml}$ after 8 weeks of spironolactone therapy). Left superior parathyroidectomy and left adrenalectomy were then performed simultaneously on December 8, 1999. An enlarged parathyroid gland of $2.1 \mathrm{~g}$ in weight, and an adrenocortical tumor were removed. The pathological diagnoses of the resected parathyroid gland and adrenal gland were parathyroid chief cell adenoma and adrenocotical adenoma with hyperplasia of zona glomerulosa, respectively (Fig. 1B and 1C). After the operation, serum calcium levels as well as plasma intact PTH declined to within the normal range. She was in good condition when she visited our outpatient clinic on April 10, 2003. She had normal serum potassium and calcium levels, and had no evidence of MENrelated neoplasia.

\section{Materials and Methods}

\section{MEN1 gene mutation analysis}

Blood was obtained from the patient after receiving written informed consent. Genomic DNA extraction from blood and MEN1 gene mutation analyses were performed as previously described (8).

Parathyroid adenoma and adrenocortical adenoma were obtained from the patient during surgery. Fresh tissues were snap frozen in liquid nitrogen and stored at $-70^{\circ} \mathrm{C}$ until later molecular analysis. Breast cancer tissue was embedded in paraffin. DNA was extracted either with a QIAamp tissue kit (Qiagen, Hilden, Germany) (parathyroid adenoma and adrenocortical adenoma) or with a TaKaRa DEXPAT ${ }^{\mathrm{TM}}$ (TaKaRa, Tokyo, Japan) (breast cancer) and amplified by PCR. Nucleotide sequencing was performed using a direct sequencing kit (Dye Terminator Cycle Sequencing Ready Reaction, Perkin-Elmer, Foster City, CA, USA) and an automated DNA sequencer (ABI PRISM 310, Perkin-Elmer).

\section{LOH analysis}

Microsatellite length polymorphism around the MENI locus was analyzed using polymorphic DNA markers on chromosome 11q13, PYGM and D11S4940, as described previously (8). PYGM and D11S4940 are located in centromeric and telomeric region, respectively, to the MEN1 gene (Fig. 2). Genomic and tissue DNA were amplified by PCR with a pair of primers, one of which was labeled with fluorescein. The amount and the size of the PCR products were determined by electrophoresis followed by measurement of fluorescence intensity using an automated genetic analyzer (ABI PRISM 310, Perkin-Elmer).

\section{Results}

Germline MEN1 gene mutation was detected at codon 541 in exon 10 of the MEN1 gene that resulted in an alanine to 

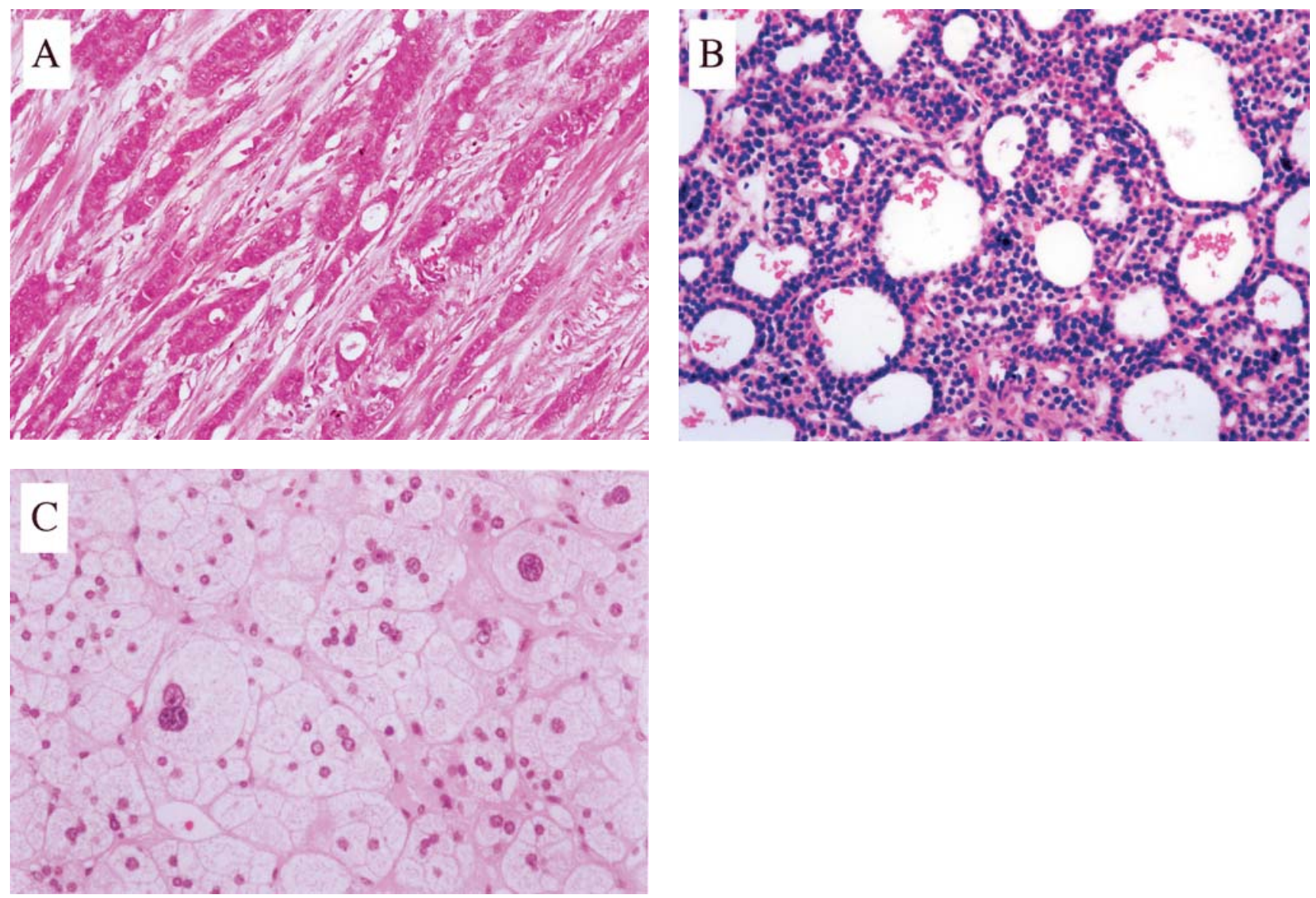

Figure 1. Photomicrographs of the tumor tissues obtained at surgery. A: breast cancer scirrhous, B: parathyroid tumor chief cell adenoma), C: adrenocortical tumor chief cell adenoma with hyperplasia of zona glomerulosa. A: HE stain ( $\times 10)$, B: HE stain $(\times 20)$, C: HE stain $(\times 20)$.

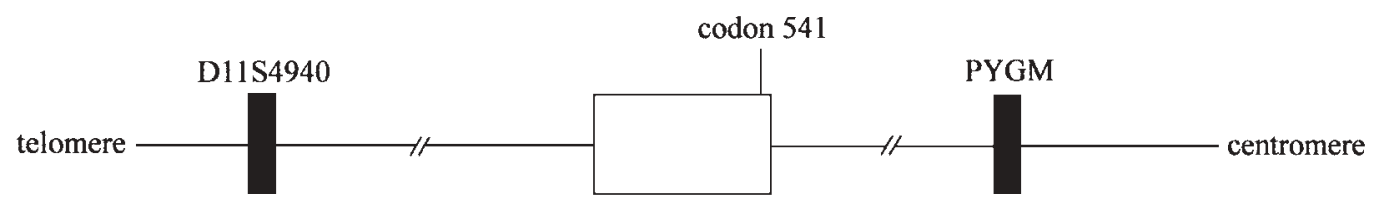

Figure 2. Schematic diagram of chromosome $11 q 13$ illustrating the relative positions of two polymorphic markers (closed boxes). Positions of the MEN1 gene (open box), and codon 541 in exon 10 are also shown. The distance between PYGM and D11S4940 is less than $300 \mathrm{~kb}$.

tyrosine substitution (A541T) in this patient (Fig. 3A). Microsatellite polymorphism analysis revealed reduced fluorescence intensity at each polymorphic site ( $P Y G M$ and D11S4940) for one of the alleles in DNA from the parathyroid adenoma (Fig. 4B). The reduced fluorescence intensity site was found only at the D11S4940 polymorphic site for one of the alleles in the breast cancer tissue DNA (Fig. 4D). Direct sequencing analyses of DNA from the parathyroid adenoma and breast cancer tissue again showed a mutation at codon 541 in exon 10 of the MEN1 gene with a $\mathrm{LOH}$ in each contralateral allele (Fig. 3B and 3D). The latter finding is in agreement with the result of the LOH study. On the other hand, LOH of the MEN1 locus was not detected in DNA from the adrenocortical adenoma tissue (Fig. 4C).

\section{Discussion}

To determine whether the development of each tumor may be associated with an alteration of the MEN1 gene, we analyzed the MENI gene in a patient with a parathyroid adenoma, an aldosterone producing adrenocortical tumor and breast cancer in the present study. Germline MENI gene mu- 


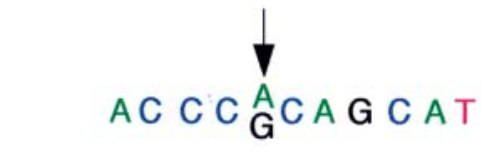

A
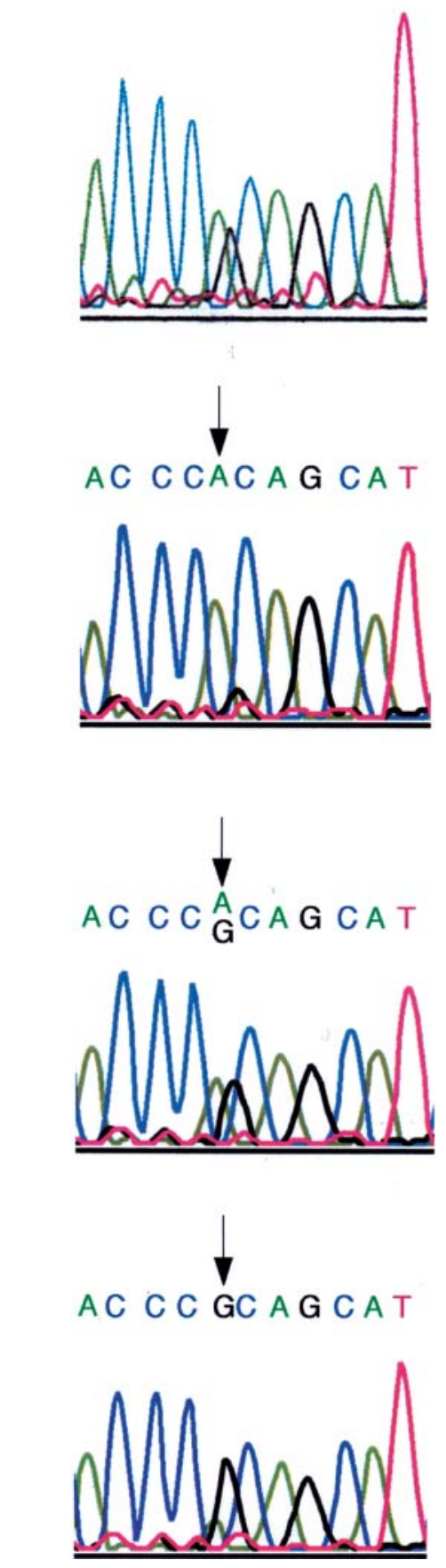

Figure 3. Direct sequence analyses showing a benign polymorphism at codon 541 in exon 10 of the MEN1 gene and a loss of the wild-type allele in the parathyroid adenoma and breast cancer tissue. A: Blood cell DNA; B: DNA from parathyroid tumor tissue; C: DNA from adreno-cortical tumor tissue; D: DNA from breast cancer tissue. Nucleotide position 541 is indicated by an arrow. tation was detected at codon 541 in exon 10 of the MENI gene in this patient. The incidence of the mutation is reported to be $24 \%$ in normal Japanese volunteers (9), thus it has been clearly demonstrated that this mutation is a benign polymorphism. Direct sequencing analyses of DNA from parathyroid adenoma, adrenocortical adenoma and breast cancer tissue again failed to show a somatic mutation in the protein-coding region of the MEN1 gene. Microsatellite polymorphism analysis near the MENI gene, however, demonstrated $\mathrm{LOH}$ in the parathyroid adenoma at both centromeric and telomeric regions to the MEN1 gene. $\mathrm{LOH}$ was found also in breast cancer tissue when the polymorphic DNA marker telomeric to the MENI gene was used. These results of the $\mathrm{LOH}$ study were in agreement with the direct sequencing analyses showing a LOH. The LOH of MEN1 gene was seen in each contralateral allele of parathyroid adenoma and breast cancer. We conclude from these observations that an alteration of the $M E N 1$ gene and/or another tumor suppressor gene located in the MENI locus on chromosome 11q13 may be involved in the development of parathyroid adenoma and breast cancer in the present patient suggesting that the clinical spectrum of MEN1 might include breast cancer. To date, $\mathrm{LOH}$ of the MENI locus in breast cancer as demonstrated in the present study has not been reported.

In the majority of MEN1 patients, a wide variety of germline mutations of the MEN1 gene has been demonstrated thus supporting the Knudson's two-hit hypothesis. Some reasons are suggested why MENI gene mutations were not found in the parathyroid adenoma or the breast cancer with LOH of the MEN1 gene. First, tumors may contain a mutation in the non-coding region of the MENI gene that was not screened. Second, there may be an alternative mechanism, such as hypermethylation of a $\mathrm{CpG}$ island, responsible for $\mathrm{LOH}$ (10). Third, another tumor suppressor gene located near the MEN1 gene on 11q13 may be involved in the development of tumors. In fact, $\mathrm{LOH}$ of the MENI gene (6) or other tumor suppressor genes (10) without somatic gene mutations, as in the present study, has been reported in other tumors such as sporadic parathyroid adenomas and clear-cell renal carcinomas. Which of the above explanations may be correct for the present patient is unknown at present.

Although MEN1 is characterized by parathyroid, pancreatic neuroendocrine, and pituitary hyperplasia or neoplasia, it is well known that tumors may occur in a variety of organs apparently unrelated to MEN in this pathologic state. One of the rare associations with MEN1 is primary aldosteronism. In earlier reports, Beckers et al (11) and Iida et al (12) studied such patients and found LOH of the 11q13 locus in aldosterone-producing adrenocortical adenomas. They concluded from these results that primary aldosteronism in their patients may be concomitant with MEN1. In the present study, LOH of the MEN1 locus was not demonstrated in the adrenocortical adenoma. These results suggest that the association of primary aldosteronism in our patient is incidental and is not related to MEN1. 
A

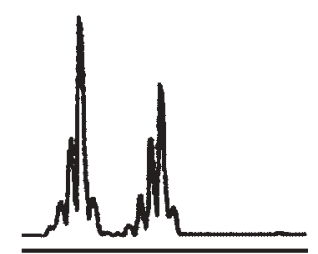

B
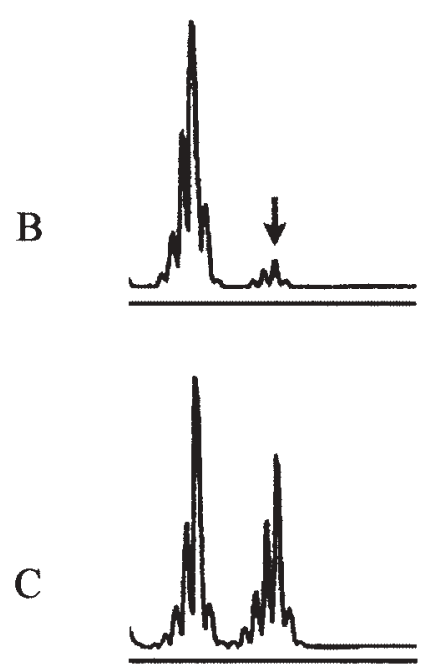

D

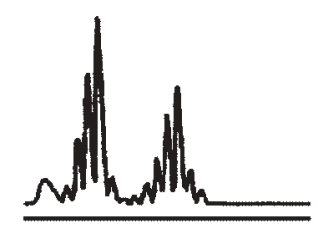

PYGM
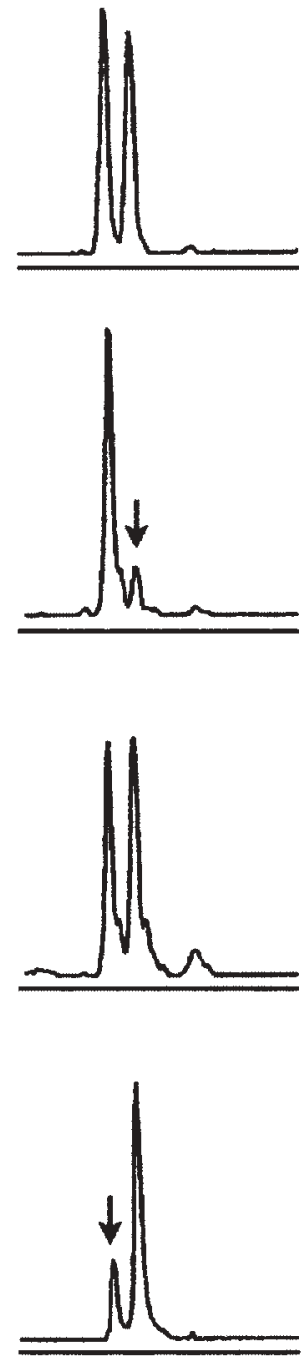

DIIS4940
Figure 4. Microsatellite polymorphism analysis using polymorphic DNA markers, PYGM and D11S4940. A: Blood cell DNA; B: DNA from parathyroid tumor tissue; C: DNA from adreno-cortical tumor tissue; D: DNA from breast cancer tissue. Arrows denote peaks with reduced fluorescence intensity in tumor compared with blood DNA.

Finally, the serum calcium concentration rose to higher levels after the initiation of spironolactone therapy in the present patient, although plasma intact PTH levels were not significantly changed. This may have resulted, in part, from the blockade by spironolactone of aldosterone actions. Excessive aldosterone induces an expansion of extracellular fluid, which, in turn, may inhibit the tubular reabsorption of calcium in the kidney, thus increasing urinary calcium excretion. Hyperaldosteronism causes hypokalemic alkalosis, which may decrease serum ionized calcium (13). Both changes may lead to lowered serum calcium levels. Of relevance are studies by Resnick and Laragh (14), and by Rossi et al (15). They reported that serum calcium levels tend to be low, and plasma PTH levels tend to be high in patients with primary aldosteronism. The abnormalities were corrected after administration of spironolactone or surgical treatment (15), suggesting that primary aldosteronism is associated with mild secondary hyperparathyroidism. Coupled with these observations, serum calcium levels should be interpreted with caution in patients with primary aldosteronism, because hypercalcemia may be masked in the presence of aldosterone excess.

\section{References}

1) Brandi ML, Marx SJ, Aurbach GD, Fitzpatrick LA. Familial multiple endocrine neoplasia type 1: a new look at pathophysiology. Endocr Rev 8: 391-405, 1987.

2) Larsson C, Skogseid B, Öberg K, Nakamura Y, Nordenskjöld M. Multiple endocrine neoplasia type 1 gene maps to chromosome 11 and is lost in insulinoma. Nature 332: 85-87, 1988.

3) Chandrasekharappa SC, Guru SC, Manickam P, et al. Positional cloning of the gene for multiple endocrine neoplasia-type 1. Science 276: 404-407, 1997.

4) The European Consortium on MEN1. Identification of the multiple endocrine neoplasia type 1 (MEN1) gene. Hum Mol Genet 6: 1177-1183, 1997.

5) Thakker RV, Bouloux P, Wooding C, et al. Association of parathyroid tumors in multiple endocrine neoplasia type 1 with loss of alleles on chromosome 11. N Engl J Med 321: 218-224, 1989.

6) Farnebo F, Teh BT, Kytölä S, et al. Alterations of the MEN1 gene in sporadic parathyroid tumors. J Clin Endocrinol Metab 83: 2627-2630, 1998.

7) Carling T, Correa P, Hessman O, et al. Parathyroid MEN1 gene mutations in relation to clinical characteristics of non-familial primary hyperparathyroidism. J Clin Endocrinol Metab 83: 2960-2963, 1998.

8) Honda M, Tsukada T, Tanaka H, et al. A novel mutation of the MEN1 gene in a Japanese kindred with familial isolated primary hyperparathyroidism. Eur J Endocrinol 142: 138-143, 2000.

9) Miyauchi A, Sato M, Matsubara S, et al. A family of MEN1 with a novel germline missense mutation and benign polymorphisms. Endocrine J 45: 753-759, 1998.

10) Herman JG, Latif F, Weng $Y$, et al. Silencing of the VHL tumorsuppressor gene by DNA methylation in renal carcinoma. Proc Natl Acad Sci USA 91: 9700-9704, 1994.

11) Beckers A, Abs R, Willems PJ, et al. Aldosterone-secreting adrenal adenoma as part of multiple endocrine neoplasia type 1 (MEN1): Loss of heterozygosity for polymorphic chromosome 11 deoxyribonucleic acid markers, including the MEN1 locus. J Clin Endocrinol Metab 75: 564-570, 1992.

12) Iida A, Blake K, Tunny T, et al. Allelic losses on chromosome band $11 \mathrm{q} 13$ in aldosterone-producing adrenal tumors. Genes Chromosom Cancer 12: 73-75, 1995.

13) Moore EW. Ionized calcium in normal serum, ultrafiltrates, and whole blood determined by ion-exchange electrodes. J Clin Invest 49: 318334, 1970.

14) Resnick LM, Laragh JH. Calcium metabolism and parathyroid function in primary aldosteronism. Am J Med 78: 385-390, 1985.

15) Rossi E, Sani C, Perazzoli F, Casoli MC, Negro A, Dotti C. Alternations of calcium metabolism and of parathyroid function in primary aldosteronism, and their reversal by spironolactone or by surgical removal of aldosterone-producing adenomas. Am J Hypertens 8: 884893, 1995. 